

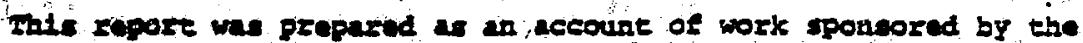
Untted stated Governimat. Watther the United States nor the United States Deparenent of Energy, nor any of thetr enployens, nor any of thoif contractors, subcontractors, or thalr exployess, makes any warranty, axpess or toplied, or assunes any legal liability or responsibility for

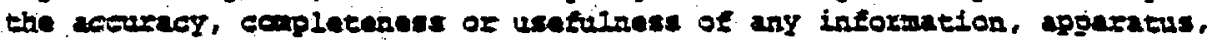
product or process disclosed, or zoprosents that its use would not infriage petrately ouned righes.

Printed in the United States of Amozick.

\section{aratiable from:}

Wational Technical Information Service -

U. 5. Department of Comerce

5285 Port Royel Road

sfriagfield, Virginia 22151

\section{Price: Printed Copy \$ \#_, Microfische $\$ 3.50$}

\section{- PAGES}

$1-25$

26-50

51-75

$76-100$

$101-125$

$126-150$

ISI-I75

$176-200$

201-225

$226-250$

25I-275

276-300

$301-325$

$326-350$

$351-375$

$376-400$

$401-425$

$426-450$

451- 475

476-500

$500-525$

$526-530$

55I-575

$576-600$

\section{MrIs}

\section{Seliling Price}

$\$ 5.00$

$\$ 6.50$

$\$ 8.00$

$\$ 9.50$

$\$ 11.00$

$\$ 12.50$

$\$ 14.00$

$\$ 15.50$

$\$ 17.00$

$\$ 19.50$

$\$ 20.00$

$\$ 21.50$

$\$ 23.00$

$\$ 24.50$

$\$ 26.00$

.\$27.50

$\$ 29.00$

530.50

$\$ 32.00$

$\$ 33.30$

$\$ 35.00$

$\$ 36.50$

$\$ 38.00$

$\$ 39.50$
For documents over 600 pages, add $\$ 1.50$ for sach additional 25 page increment. 
Ion-Beam-Driven Electrostatic Ion

Cyclotron Instabllities

\author{
A. Miura ${ }^{*}$ \\ Institute of Ceophysics and P1anetary Physics \\ Iniversity of California \\ Los Angeles, California 90024 \\ H. Okude \\ Plasma Physics Laboratory, Princeton University \\ Princeton, New Jersey 08544
}

M. Ashour-Abdalla

Department of Physics and Institute of Ceophysics and Planetary Physics

Untversity of Callfornta

Los Angeles, Callfornta 90024

\begin{abstract}
We present results of numerical simulations on the electrostatic ion cyclotron instabilities driven by the lon beam parallel to the magnetic fleld. For the beam speed exceeding the thermal speed of background ions and the beam temperature much lower than the hackground fon temperature, it is found that the instablity results in strong perpendicular heating and slowing down of parallel drift of the beam lons, leading to the saturation of the 1nstability. Applications ic plasma heating and space plasma physics are discussed .

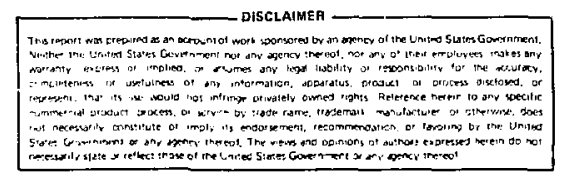

*On leave fromi: Geophysics Research Laboratory, Untverst.ty of Tokyo, Bunkyoku, Tokyo, 113 Japan
\end{abstract}




\section{Introduction}

Recently, there is a growing interest in the study of electrostatic 1oncyclotron (EIC) waves driven by an lon beam parallel to magnetic fleld. One such example Is a space plasma near $1 R_{E}$ altitude on the auroral field line with regard to the mechanisms causing strong perpendicular heating of lons observed in situ at this altitude ( $E \cdot g .$, Sharp et al., 1977). Another example is a fusion plasma subject to strong neutral beam 1njection (St1x, 1973). For the case of auroral plasmas, there are at least two energy sources driving EIC waves at this altitude (Kintner et al., 1979): one is the electron paralle] drift and the other is the fon beam parallel to the magnetic field. The instahility driven by parallel electron drift has been studied extenstvely in both linear (Drummond and Rosenbluth, 1962; Kindel and Kennel, 1971) and nonlinear (e.g., Okuda et al., 1981; Okuda and Ashour-Ahdalla, 1981, 1982; Lysak et al., 1980) regimes. In contrast, the study of the lon beam driven EIC wave has remalned malnly in the linear reglme (Weibel, 1970; Perkins, 1976; Yamada et al., 1977; Kaufman and Kintner, 1982), although the understanding of the nonlinear consequence of the Instabiltey is essential in estimating plasma heating and beam slowing down. For the case of an auroral plasma, it has been established experimentally that the EIC waves are assoclated with parallel ton beam near $1 R_{E}$ altitude (Shelley et al., 1976; Kintner et al., 1979; Gorney et al., 1981; Cattel1, 1981; Temerin et al., 1981 ; Mizera et a1., 1982).

The purpose of this letter is to report the inftial results of the particle simulation study of the EIC Instability driven by the parallel fon beam. While the current-driven EIC wave is driven by the Inverse"electron randau damping by the drifting electrons, the ion beam can destabtlize EIC waves both by resonant (Perkins, 1976; Yamada et al., 1977) and nonresonant 
(Weibe1, 1970) interactions. The resonant case drivell by the inverse ton Landau damping has the lowest thresholia; however, the growth rate for this case is smaller than that driven by a reactive coupling between beam cyclotron modes and background lon cyclotron modes (Perk1ns, 1976). For the resonant case, the Instability occurs at $w / k_{\|} \sim u_{b}$, where $u_{b} 1 s$ the ton beam velocity relative to the background lons: on the other hand, the nonresonant case is characterlzed by the phase velocity $w / k_{\|} \sim u_{b} / 2$ (Yamada et al., 1977). On auroral fleld lines near $\operatorname{lR}_{E}$ altitude, the lon beam has been observed to have a drift velocity typlcally a few hundred $\mathrm{km} / \mathrm{sec}$ (Kintner et al., 1979; Mizera et al., 1982), suggesting that the observed fon beam is accelerated upward by a potential difference of a few KeV existing below $l R_{E}$ altitude. For such a large parallel bean velocity exceeding the thermal speed of lons of ionospheric origin $\left(u_{b} \gg v_{t \| l}\right)$, the lastability condition is easily satisfled and we expect that the parallel ion beam is a viable energy source for the EIC waves observed at $1 \mathrm{R}_{\mathrm{E}}$ altitude (Mozer et al., 1977; Kinter et al., 1979).

\section{Lnear Theory}

The dispersion relation for the Ion beal driven EIC waves (Yamada et al., 1977) In a three components plasma is given by

$$
\begin{aligned}
& 1+\frac{1}{k^{2} \lambda_{e \|}^{2}}+\frac{1}{k^{2} \lambda_{t \|}^{2}}\left[1+\sum_{n=-\infty}^{\infty} \Gamma_{n} \frac{\omega-n \Omega_{1}\left(1-T_{t \| l} / T_{t 1}\right)}{k_{\|} v_{t \|}} z\left(\frac{\omega-n \Omega}{k_{\|} v_{t \|}}\right)\right] \\
& +\frac{1}{k^{2} \lambda_{b \|}^{2}}\left[1+\sum_{n=-\infty}^{\infty} \Gamma_{n} \frac{\omega-k_{\|} u_{b}-n \Omega_{1}\left(1-T_{b \|} / T_{b L}\right)}{k_{\|} v_{b l}} z\left(\frac{\omega-k_{n} u_{b}-n \Omega_{1}}{k_{\|} v_{b \|}}\right)\right]=0,
\end{aligned}
$$

where $u_{b}$ is the lon beam speed, $\Omega_{1}$ is the ion gyrofrequency, $r_{n}\left(\mu_{1}\right)=$ $\exp \left(-\mu_{1}\right) I_{n}\left(\mu_{1}\right), \mu_{1}=k_{1}^{2} v_{11}^{2} / 2 \Omega_{1}^{2} \equiv k_{1}^{2} \rho_{1}^{2}, T_{t !}$ and $T_{t \perp}$ are parallel and 
perpendicular temperatures of background (target) ions, $r_{b \| l}$ and $T_{b \perp}$ are parallel and perpendicular temperatures of beam tons, $v_{e}=\left(2 T e^{/ m}\right)^{1 / 2}$, $v_{t H}=\left(2 T_{t \| l} / M\right)^{1 / 2}, \quad v_{b \|}=\left(2 T_{b \|} / M\right)^{1 / 2}, \lambda_{e \|}=v_{e \| l} / \sqrt{\tau_{\omega}}{ }_{p e}, \lambda_{t \|}=v_{t \|} / \sqrt{2} \omega_{p t i}$, $\lambda_{b \|}=v_{b \|} / \sqrt{2} \omega_{p b 1}$, and $z$ is the plasma dispersion function. In (1) we have neglected a small term due to the electron Landau damping by the assumption $\omega / k_{H} \ll v_{e \| l}$, but Instead we have included the effect of anisotropic biMaxwellfan tons by introducing parallel and perpendicular temperatures. One of the nonlinear consequences of the fon cyclotron instability is the generation of temperature anisotropy by perpendicular ion heating. Therefore, Eq. (1) may be used to determine the maximum temperature anisotropy $T_{1} / T_{\|}$from the marginal stability condition for a given drift speed (Okuda and AshourAbdalla, 1981, 1982).

For the case of resonant interaction we retaln only $n=0$ for beam lons and $n=I$ for background ions in (1). Then, assuring that $\left|\left(\omega-k_{\|} u_{b}\right) / k_{\|} v_{b \|}\right|<<$ 1 and $\left|\left(\omega-\Omega_{1}\right) / k_{\|} v_{t \|}\right| \gg 1$, we obtain

$$
\frac{\omega-\Omega_{1}}{\Omega_{i}}=\Gamma_{1}^{t}\left(\frac{n_{i b}}{n_{i t}} \frac{T_{t \perp}}{T_{b \|}}+\frac{n_{e}}{n_{i t}} \frac{T_{t \perp}}{T}\right)^{-1} \text {, }
$$

where $n_{i b}, n_{1 t}, n_{e}$ are densttles of beam lons, background lons, electrons, and $\Gamma_{1}^{t}$ is defined by the background ions. Therefore, when the bean is cold $\left(T_{b \|} \ll T_{t \| l}\right)$, we find the frequency $\omega \geqslant \Omega_{1}$ for $n_{1 t} \sim n_{1 b}$.

For nonresonant interaction the instability is driven by the coupling between slow wave (negative energy wave) on the ton beam and lon cyclotron mode on background lons. Therefore by retalning $n=1$ for background lons and $n=-1$ for beam ions and assuming $\left|\left(\omega-\Omega_{i}\right) / k_{\|} v_{t \mid}\right| \gg 1$ and $\left|\left(\omega-k_{\|} u_{b}+\Omega_{1}\right) / k_{\|} v_{b \|}\right| \gg 1$, we obtain 


$$
\frac{\omega-\Omega_{1}}{\Omega_{1}}=-2\left(1-\frac{k_{11} u_{b}}{2 \Omega_{1}}\right) \frac{1}{1-\left(\Gamma_{-1}^{b} / \Gamma_{1}^{t}\right)\left(T_{t \perp} / T_{t \|}\right)\left(n_{i b} / n_{1 t}\right)\left(T_{b \|} / T_{b 1}\right)} \text {, }
$$

whe=e $\Gamma_{-1}^{b}$ and $\Gamma_{1}^{t}$ are defined by bean tons and background ions, respectively, and the term from the electron shielding is neglected assuming $w \approx \Omega_{1}$. This predicts that as $\mathrm{T}_{\mathrm{b} \|} / \mathrm{T}_{\mathrm{b} \perp}$ approaches to zero as a result of perpendicular heating of Ion beams by the EIC wave, $w$ approaches to $\Omega_{1}$, Increasing the cyclotron damping of waves by background lons. In the 11 mit $\omega+\Omega_{1}$ we obtain from (3) $w / k_{k} \sim \Omega_{1} / k_{\downarrow} \sim u_{b} / 2$. In the beam frame, the frequency is biven by

$$
\omega-k_{\|} u_{b} \approx \Omega_{1}-2 \Omega_{1}=-\Omega_{1} \text {. }
$$

Therefore, in the same 1 Imit $T_{b \|} / T_{b \perp}+0$, the cyclotron damping by beam lons also increases. These results suggest that in the nonlinear stage of the nonrsonant case, if the lons are heated preferentially in the perpendicular direction, the destabilizing term due to the nonresonant reactive cyclotroncyclotron coupling is balanced by cyclotron damping of waves by hackground (target) lons and beam ions.

III. Simulation Results

Here we consider a three component plasma consisting of background electrons, background lons, and beam lons. We assurae Maxwellian diatributions for both electrons and background lons, and a drifting Maxwellian distribution for the Ion beam with beam speed $u_{b}$.

The stmulation code used is a one spatial dimension and 3 velocity dimensions (Lee and Okuda, 1978). This code uses the drift kinetic approximation for electrons $\left(k_{\perp} \rho_{L e} \ll 1\right.$ and $\left.\omega \ll 8_{c e}\right)$, but retains the full 
ion dynamics in 3-D velocity space. Parameters used in the simulations are $L$ (system length) $=128 \Delta, \Delta=$ electron Debye length, $\mathrm{a} / M=1 / 1837$, and $\omega_{\mathrm{pe}} \Delta t=$ 2.0. In accordance with the S3-3 data neat $1 R_{E}$ altitude, we use $T_{e}=T_{1 t}$ $=T_{t \|}=T_{t L}, T_{1 b}=T_{b H}=T_{b L}=T_{i t} / 16, k_{\|} / k_{\perp}=0.1 n_{1 b} / n_{1 t}=1.0, \omega_{c e} / \omega_{p e}=$ 2.0 , and $u_{b}=20 v_{t l l}$.

Figure 1 shows profiles in the $x$ direction of the electrostatic potential $e \phi / T_{e}(1-a)$, electron density $n_{e}(1-b)$, background ion density nit $(1-c)$, and beam Ion density $n_{i b}(1-d)$ at $R_{1} t=160$. A coherent wave with a single wave period is seen in all profiles. Note that the varlations in $n_{e}, \phi$, and $n_{1 b}$ are almost in phase, while those between $n_{t t}$ and $n_{1 b}$ are almost out of phase. The wave amplitude in $n_{1 b}$ is larger than that in $n_{1 t}$. As we w111 see later, the beam ions are heated strongly with a large increase in $T_{\perp}$ by this time.

Figure 2 shows frequency spectra in the rest frame (frame of electron background) of the 1 st and $3 r$ d modes for linear phase, $0<8_{1} t<40(2-a, c)$ and for later pertod, $0<\Omega_{1} t<160(2-b, d)$. In Fig. 2-a, the peak of the frequency spectrum of the lst mode occurs below the lon cyclotron frequency. However, for the later period (FIg. 2-b), the peak of the spectrum of the lst mode occurs at $\omega \geq \Omega_{1}$. This nonlinear frequency shift of the $E I C$ wave from $\omega<\Omega_{1}$ to $\omega \geqslant \Omega_{1}$ gives $\mathrm{r}$ ise to a perpendicular heating of background and beam lons, causing damping of the EIC wave. For the 3rd mode, the frequency spectra (Figs. 2-c and 2-d) occurs at harmonics of $\Omega_{1}$.

Since the parallel phase velocity $\omega / k_{\|}$shows us whether the instability 1s driven by resonant interaction or by nonresonant interaction we should check $\omega / k_{\|}$by the sioulation results. For the peak spectrum for the ist and 3rd modes shown in Fig. 2-a and c, we obtain 


$$
\omega / k_{\|}=0.38 u_{b}, 0.64 u_{b} .
$$

Therefore, for the present simulation parameters with a large beam velocity, the paraliel phase veloctty is well below the lon beam velocity, nearly equal to one-half of the heam velocity, and the EIC waves are destabilized essentially by nonresonant interaction between beam cyclotron mode and cyclotron mode on the background lons (We1bel, 1970).

We show in Fig. 3 perpendicular and parallel velocity distrabutions for background ions $(3-a, b)$ and beam lons $(3-c, d)$. Stnce the electron contribution is only to give a small Landau damplag, the electron velocity distribution was found to suffer a neglibible change.

While the perpendicular heating of backiground tons remains small (Fig. 3a), the beam lons are heated strongly (Fig. 3-c). Figure $3-d$ shows that the Ion beam is decelerated in the parallel direction by the Instability which, at the same time, caused diffusion in the beam parallel velocity.

Shown in Fig. 4 are contours of particle distribution in the velocity space $\left(v_{x}-v_{\|}\right)$for background fons $(4-a, b)$ and for beam fons $(4-c, d)$ at $t=0$ and $\Omega_{1} t=160$. Initially the beam is cold $\left(T_{1 b}=T_{1 t} / 16\right)$ and cotroplc; however, the beam lons are heated strongly in the perpendicular direction (4d) and form an anisotropic distribution. The perpendicular temperature of beam lons at the final stage becomes about 30 times larger than 1 ts lnitlal temperature. The background lons are also heated in the perpendicular direction $(4-b)$ with $T_{t \perp}\left(Q_{t} t=160\right) / T_{t I}(t=0) \sim 3$. It should be noted that In the final stage the velocity spread in the perpendicular direction becomes comparable for both background and beam lons, and the equipartion of perpendicular energy between two ton components is realized.

We have shown in $\mathrm{FH}_{\mathrm{g}}$. 3 that, along with the perpendicular heating, the 
orfginal beam velocity slows down, and the diffusion in the parallel velocity occurs by the instability. Since this slowing down of the lon beam is one important feature of the ion beam driven EIC Instability (Yailada et al., 1977), we show in $\mathrm{Fg} .5$ the parallel mean velocity of bear lons $\mathrm{u}_{\mathrm{b}}$, the parallel mean velocity of background lons, and the parallel mean velocity of electrons multiplfed by $\pi / M$. The loss of parallel momentum of the beam ions is compensated by the increas: In the mean parallel velocity of the background lons with a small momentum going tnto background electrons. The ririft velocity of the background tons reaches $0.4 v_{t \pi}(t=0)$ and reduces the relative parallel velocity between beam tons and background tons. Since this decrease in the bean velocity is quite small $\Delta_{b} / u_{b} \sim 0.04$, this process does not seem to be a dominant stabilizing factor, although such a heam slowing down may be a dominant stabilizing factor in the resonant case Ariven by a small beam velocity (Yamada et al., 1977).

If we neglect the momentum exchange between ions and electrons, we can define the parallel anomalous collision frequency between background ions and beam ions by

$$
v_{\text {eff } \|}=\frac{1}{2} \frac{d}{d t}\left\langle v_{t \|}\right\rangle /\left(\left\langle v_{t \|}\right\rangle-\left\langle v_{b \|}\right\rangle\right),
$$

which leads to the anowalous slowing down of beam lons. From Fig. 5 we obtaln In the linear stage

$$
v_{\text {eff } \|} \sim 5 \times 10^{-5} \Omega_{1}=5.4 \times 10^{-8} \omega_{p e} .
$$

Therefore the ion beam slows down with a time constant $\nu_{\text {effll }}^{-1} \sim 2 \times 10^{4} \Omega_{1}^{-1}$. If we compare $v_{\text {eff }}^{-1}$ with the classtcal electron-drag "slowing down time" $t s$ 
for hydrogen Ion (Spitzer, 1962; Stix, 1973)

$$
t_{s}=6.27 \times 10^{8}\left[\left(\mathrm{kT}_{e}\right)^{3 / 2} / \mathrm{n}_{\mathrm{e}} \ln \Lambda\right] \mathrm{sec},
$$

where $\mathrm{kT}_{e}$ is in $\mathrm{eV}$ and $\mathrm{r}_{\mathrm{e}}$ is $\mathrm{in} \mathrm{cm}^{-3}$, which is valld for $v_{t \|}<u_{b}<v_{e l l}$, $u_{b}$ $\gg(M / m) v_{e}$, we obtaln, for parameters near $I R_{e}$ altitude, $n_{e}=10 \mathrm{~cm}^{-}$ $3, \Omega_{1} \sim 600 \mathrm{sec}^{-1}, \ln \Lambda \sim 20, \mathrm{kT}=1 \mathrm{eV}$,

$$
\nu_{\text {effut }} t_{s} \sim 10^{5}
$$

Therefore the anomalous slowing down of the beam lons 1 s $10^{5}$ times larger than the classtcal value.

It is also known that under the presence of the EIC wave, the cross field diffulon of lons arlses due to wave-particle resonances (Okuda et al., 1981). Since this wave-particle resonance leads to the perpendicular heating of Ions, we thay define the anomalous perpendicular colliston frequency $v_{\text {eff } \perp}$ by

$$
v_{\text {eff } \perp}=\frac{1}{T_{\perp}(t=0)} \frac{d T}{d t} .
$$

he show in Fig. 6 perpendicular temperatures of beam and background ions normalized by their intial values as a function of time. From these curves we obtatn for beam lons $v_{\text {eff } L}^{b}=0.2 \Omega_{1}$ and for background lons $v_{\text {eff } 1}^{t}=0.032 \Omega_{1}$. Thus, the beam tons diffuse more rapidly perpendicular to the magnetic fleld than the background lons. Since the beam fons flowtig along the magnetic field transfer thetr parallel momentum across the magnetic field by this anomalous cross field diffusion, there is an anomalous momentum 
transfer across the inagnetic fleld, which should be measured as a viscosity. If we define the anomalous viscosity by $\mu_{\text {eff }} \sim \rho_{\mathrm{LI}}^{2}{ }_{\mathrm{eff}}^{\mathrm{b}}$, we obtain $\mu_{\text {eff }} \sim 0.2 \mathrm{P}_{\mathrm{L}^{2}}^{2} \mathrm{\Omega}_{1}$, "hich is as large as the Bohm diffusion $\mathrm{D}_{\mathrm{B}}=(1 / 16)\left(\mathrm{T}_{\mathrm{e}} / \mathrm{eB}\right)$.

\section{Discussion}

The present simulation study demonstrates a nonlinear consequence of nonresonant EIC waves destabilized by ion beam parallel to the magnetic field for the case of a large beam veloctty $\left(u_{b}=20 v_{t \| l}=0.5 v_{e}\right)$. As a consequence of the instability, the leam tons are heated strongly in the perpendicular direction aric suffer a strong anomalous friction via EIC waves which leads to the beara slowing down. In the linear phase, the peak frequency spectrum occurs below $\varsigma_{1}$. In the nonlinear stage, however, the frequency of the peak spectrum shifts to $2 \Omega_{1}$, causing large cyclotron damplng of waves by the background (target) Ions and beam 1onj. Since the parallel phase velocity wik occurs at $\sim \mathrm{u}_{\mathrm{b}} / 2$, the instability in the present case is destabilized essentially by nonresonant interaction between beam ion cyclotron mode and background (target) ion cyclotron mode. We find from simulation results that the anomalous slowing down of bean lons by EIC waves is much larger than that by the classical eiectron-drag, and the perpendicular collision frequency (viscosity) measured from the perpendicular beam heating is as large as that of Bohm diffusion which agrees with the result observed for the electron drift driven EIC Instability (Okuda et al., 1981).

We should point out here that when the ion bean speed is not so large, the instability may be more favorably dastabilized by resonant interaction between beam acoustic mode and background lon cyclotr:n mode, which is destab1lized by a smaller beam speed (Perkins, 1976). Nevertheless, we expect 
that two important consequences of the instability revealed by the present simulation, $1 . e .$, perpendicular heating of lons and beam slowing down, are intrinsic to the ion bean driven EIC Instability and are responsible for the saturation of the instability.

Our results presented here demonstrate that the ion beam driven EIC wave is a viable mechanism to transfer the fon parallel beam energy to the fon perpenolcular energy. These results are consistent with the s3-3 observations near $1 R_{E}$ altiture on the auroral fleld line, whtch have showt exlstence of upstreaming lons having an anisotropic velocity distribution or a contc distribution, in which $T_{b i}$ exceeds greatly $T_{b \| l}$, in close assoctation with strong FIC waves. 


\section{Acknowledgments}

This work was carried out while one of the authors (A.M.) was visiting the Flasma Physics laboratory of Princeton University. He would like to thank the staff members of the laboratory for leir kind hospltality durirg his stay. The authors would like to thank Dr. C. Z. Cheng and Dr. F. W. Perkins for helpful discusstons and Dr. D. J. Gorney for informing us if S3-3 ion data. Thls work was supported by the Nattonal Sclence Foundation Grant ATM8115257 and the United States Departinent of Energy Contract No. DE-ACO2-76Cll03073 at Princeton UnIversity and by NASA Solar Terrestrial Theory Program Grant NAGW78 at The University of California, Los Angeles. 
References

Cattel1, C., J. Geophys. Res., 86, 3641, 1981 .

Drummond, W. E., and M. N. Rosenbluth, Phys. Flulds, 5, 1507, 1962.

Gorney, D. J., A. Clarke, D. Croley, Jr., J. Ferne11, J. Luhmann, and

P. Mizera, J. Geophys. Res., 86, 83, 1981.

Kaufmann, R. L., and P. M. Kintner, submitted to J. Geophys. Res., 1982.

Kinde1, I. M., and C. F. Kennel, J. Geophys. Res.e 76, 3055, 1971.

Kfntner, P. M., M. C. Kelley, R. D. Sharp, A. G. Ghlelmett, M. Temerin,

C. Catt.o11, P. F. Mizera, and J. F. Fenne11, J. Geophys. Res.2 84, 7201, 1979 .

Lee, H. H., and H. Okuda, J. Compt. Phys.2 26, 139, 1978.

Lysak, R. L., M. K. lludson, and M. Temerir, J. Geophys. Res., 85, 678, ?980. Mizera, P. F., D. J. Gorney, and J. F. Fennell, J. Geophys. Res., 87, 1535, 1982 .

Mozer, F. S., C. W. Carlson, M. K. Hudson, R. B. Torbert, B. Parady, J. Yatteau, and M. C. Kelley, Phys. Rev. Lett:2 38, 292, 1977.

Okuda, H., C. Z. Cheng, and I. W. Lee, Phys. Rev. Lett., 46, 427, 1981 . Okuda, H., and M. Ashoul:-Abda11a, Geophys. Res. Lett., 8, 811, 1981; also submitted to J. Geophys. Res., 1982.

Perkins, F. W., Phys. Fluids, 19, !.012, 1976.

Sharp, R. D., R. G. Johnson, and E. G. Shelley, J. Geophys. Res., 82, 3324 , 1977.

Shelley, E. G., R. D. Sharp, and R. G. Johnson, Geophys. Res. Lett., 3, 654, 1976.

Spitzer, L., Jr., Physics of Fully Ionfzed Gases (Interscience, New York, 1962) p. 135.

St1x, T. H., Phys. Flu1ds, 16, 1922, 1973. 
TemerIn, M., C. Cattell, R. Lysak, M. Hudson, R. B. Torbert, F. S. Mozer, R. Sharp D., and P. M. K1ntner, J. Geophys. Res., 86, 11278, 1981 .

Weibel, E. S:, Phys. Flu1ds, 16, 1922, 1973.

Yamada, M., S. Seller, H. W. Hendel, and H. Ikez1, Phys. Flutds, 20, 450, 1977. 


\section{Figure Captions}

Fig. 1. Spatial profiles in the $x$ direction of (a) electrostatic potential $e \phi / T_{e},(b)$ electron density $n_{e}$, (c) background ion density $n_{i t}$, and (d) beam A... Iensity $\mathrm{n}_{1 \mathrm{~b}}$ at $\Omega_{1} \mathrm{t}=160$.

Fig. 2. Frequency spectra of (a) 1st mode for $0<\Omega_{1} t<40$, (b) 1st mode for $0<\Omega_{i} t<160$, (c) 3 rd mode for $0<\Omega_{i} t<40$, and (d) 3rd mode for $0<\Omega_{1} t<160$.

Fig. 3. Ton velocity distributions at $\Omega_{f} t=0$ and 160 . (a) perpendicular distribution of background ions, (b) parallel distribution of hackground lous, (c) perpendicular distribution of beam fons, and (d) parallel distribut on of beam Ions .

Fig. 4. Contour plots of particle distrfbutions in the velocity space $\left(v_{1}-v_{n}\right)$ of (a) background ions at $t=0$, (b) background ions at $\Omega_{I} t=160$, (c) beam tons at $t=0$, and (d) beam fons at $\Omega_{1} t=160$.

Fig. 5. Time evolution of the parallel mean veloctly of beam tons $u_{b}$, the parallel mean veloctty of backgzound fons, and the parallel mean velocity of electrons multiplied by $m / 11$.

Fig. 6. Time evolution of the perpendicular temperatures of beam lons and background fons. 

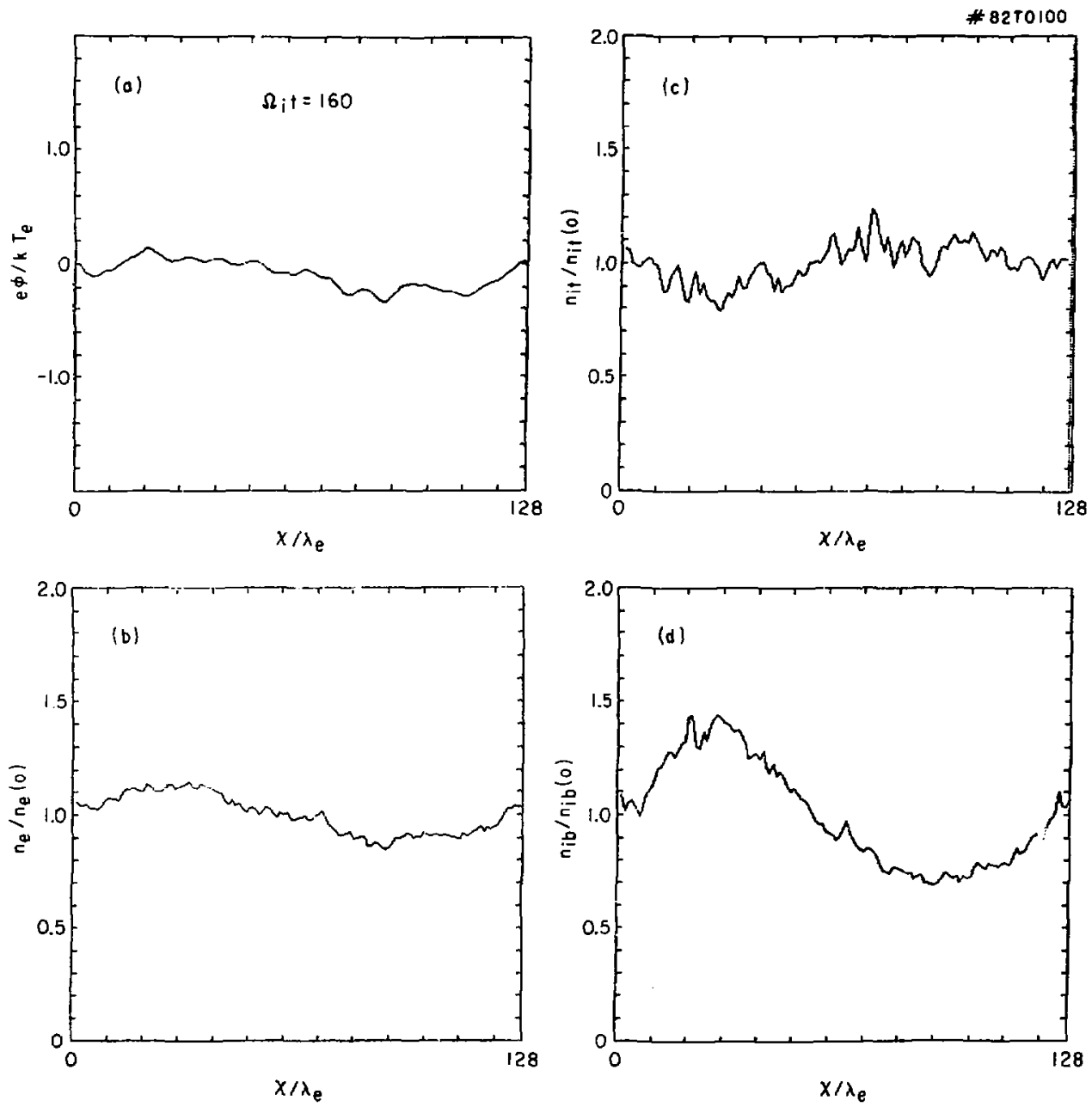

Fig. 1 

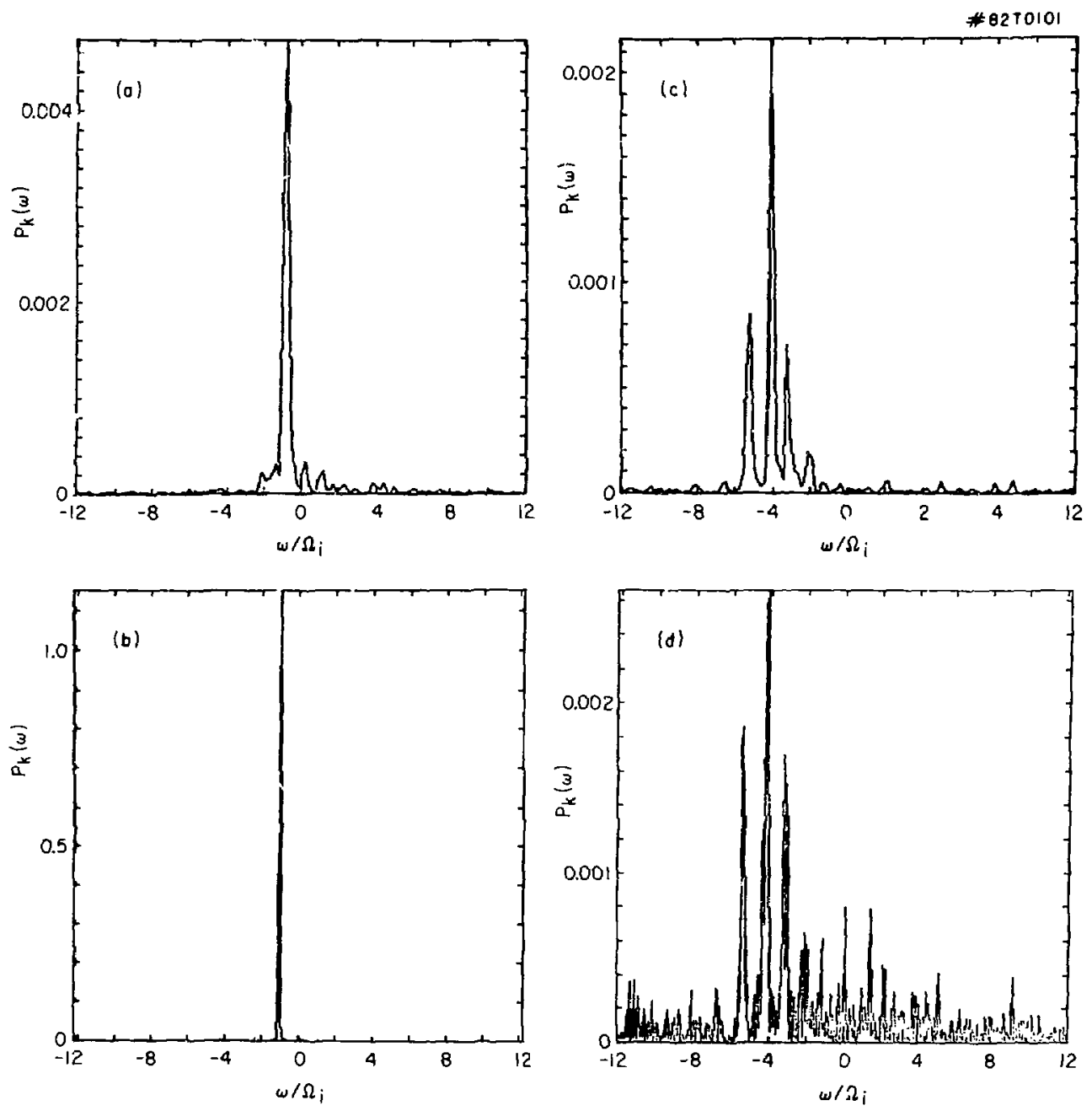

Fig. 2 

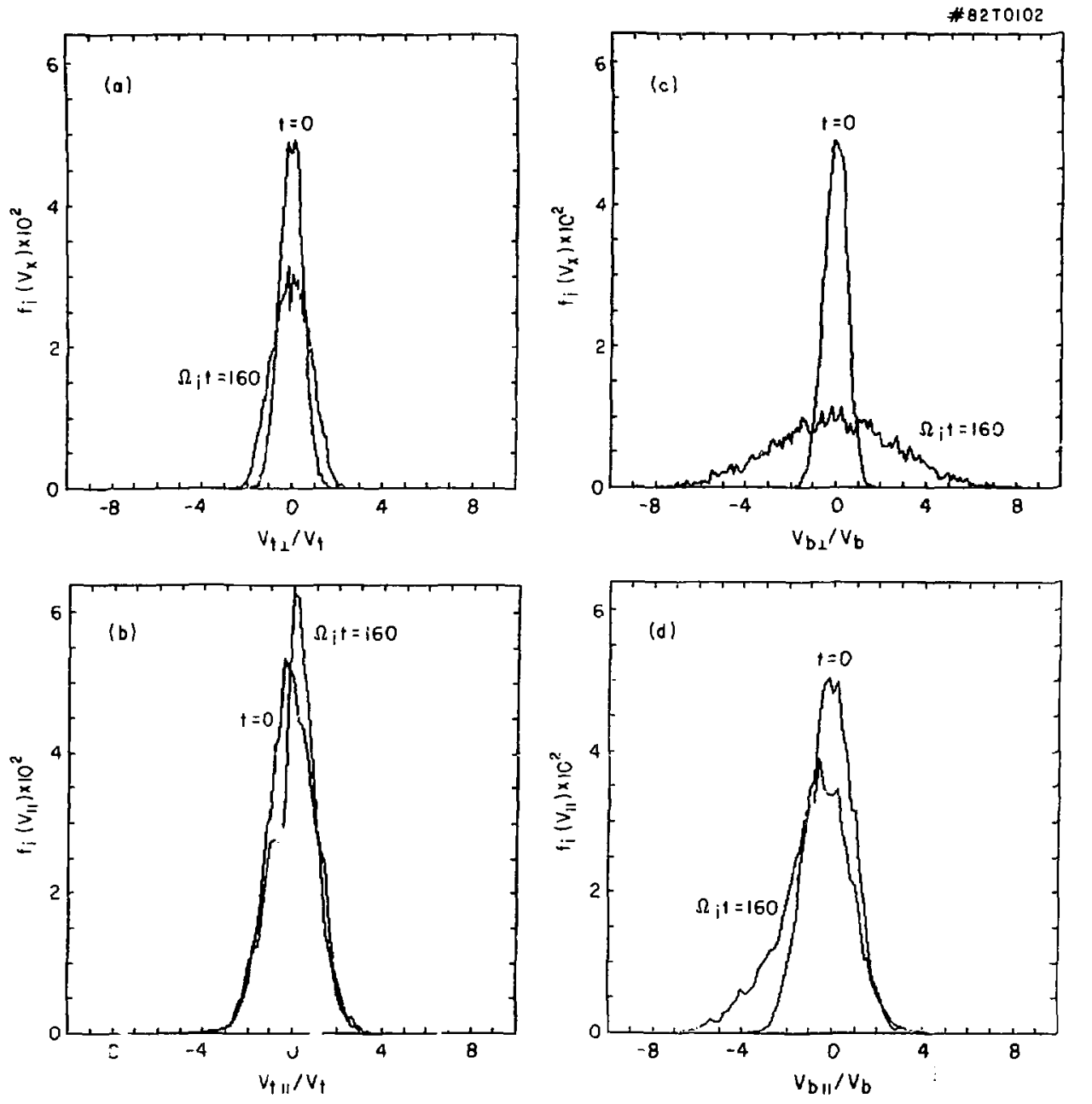

Fig. 3 

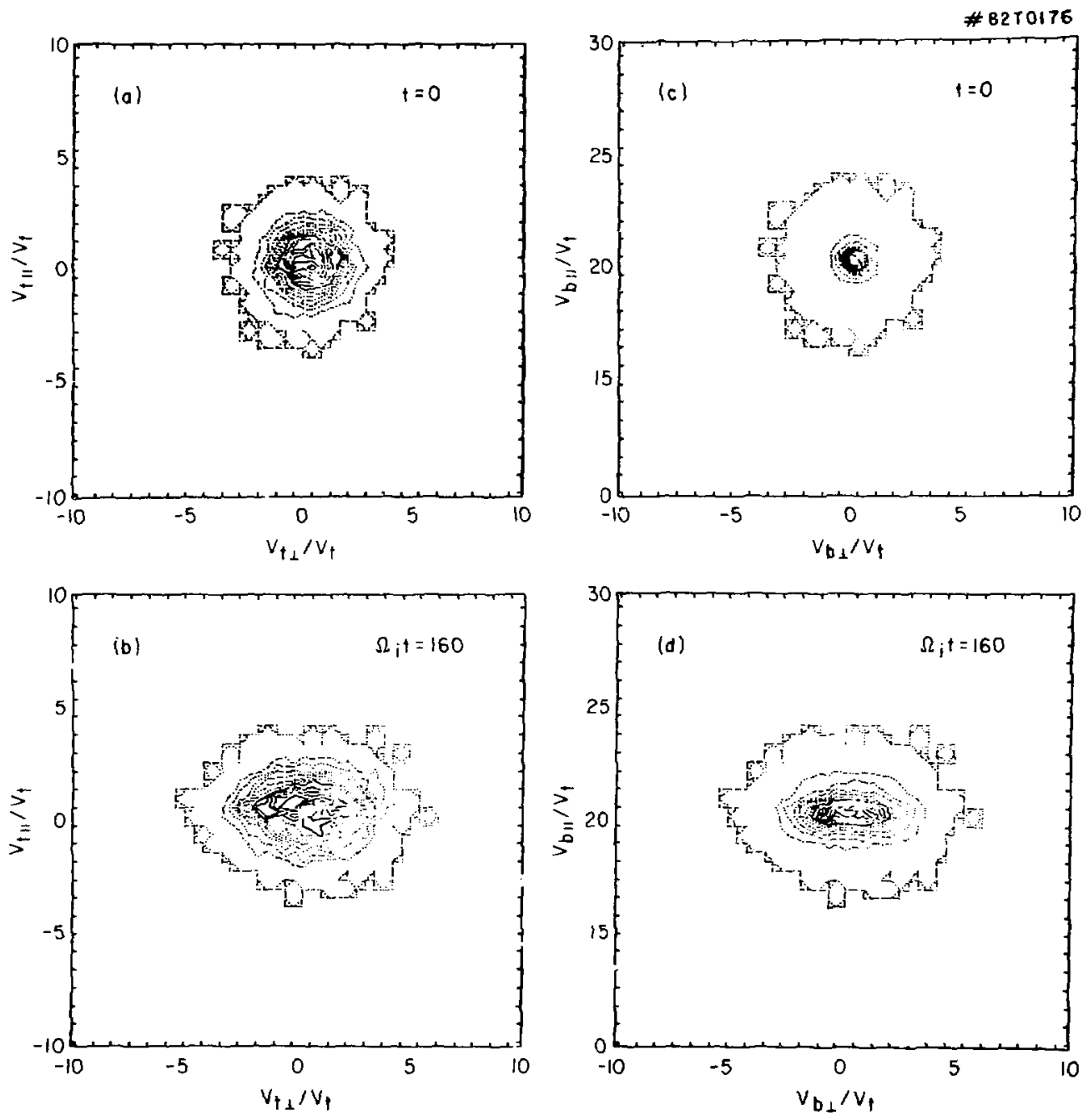

Fig. 4 


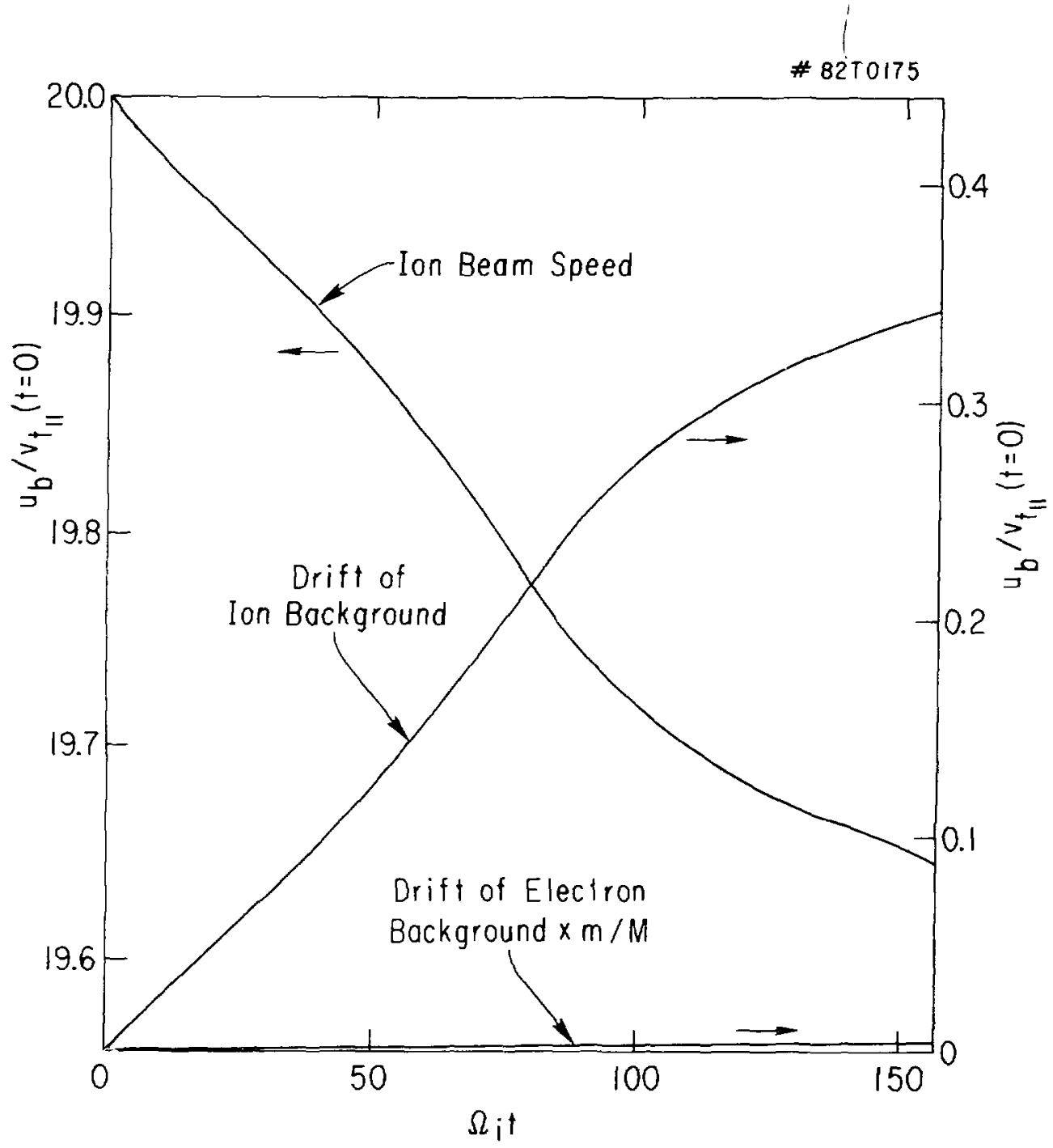

Fig. 5 


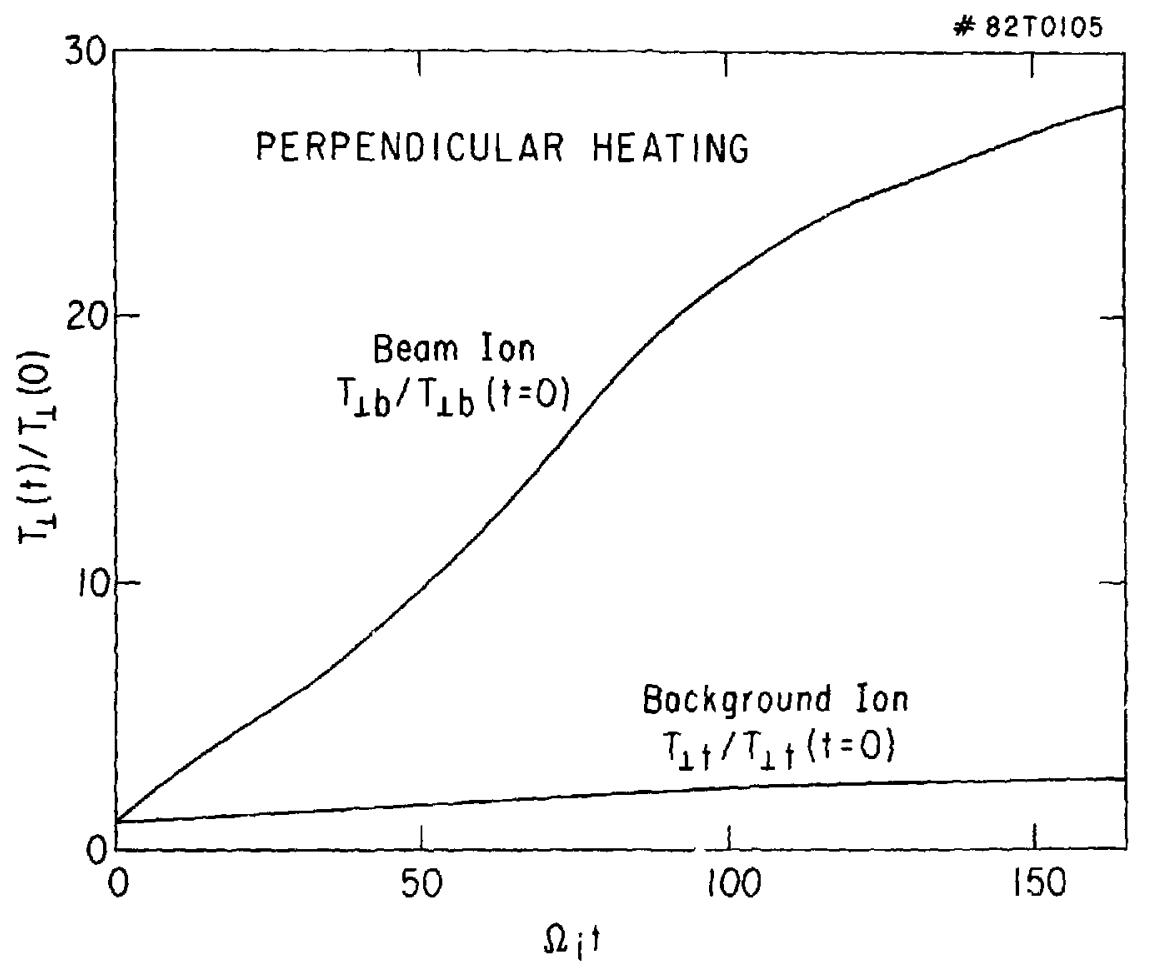


Plosmb Res Lob, Austro Nat'i Univ, ALSTRAl IA Dr. Frank J. Psoloni, Unir si Wollougong, AUSTRALIA Prof. I.R. Jones, Flinders UnIv., ALSTRAL IA Prot, M.H. Brensen, Univ Syoney, AUSTRAL IA Prof. F. Cop, Inst Theo Phys, Austria Prof. Fronk Verheest, Inst theoretische, BELGIL Dr. D. Palumbo, Dg XII fusion Prog, BELGIUM Ecole Royole Milltaira, Lab de Phys Plasmes, BELCilum Dr. P.H. Sakonaka, UnIv Estodual, BRAZIL Or. C.R. James, Univ of Alberta, CANADA Prot. J. Teichmann, Univ of Montreal, CANADA Dr. H.M. Skarsgard, Unlv of Soskatcheman, CANADA Prof. S.R. Sreenivoson, Lniversity of Calpory, CANADA Prof. Tudor W. Johnston, INR5-Energi e, CANADA Dr. Hannes Barnard, Univ Arltish Calumbla, CANADA Dr. M.P. Bachynskl, MPB Tochnologlos, Inc., CANADA Zhenguru LI, SW Inst Physlcs, CHINA

Library, Tsing Hud University. CHINA Librarian, Institute of Payslcs, CHINA Inst Plesma Phys, SW Inst Physles, CHINA Dr. Petar Lukac, Komenskaho Univ, CZEChOSLOvakia The Librarian, Culhem Laboratory. ENGLAND Prot. Schatzman, Observatolre de Nice, FRANCE J. Radet, CEN-BP6, FRANCE AM Dudas Library, AM Dupas LIbrary, FRANCE Dr. Tom Mual. Acodemy EIbliographlc, HONG KONG Preprint Library, Cent Res Inst Phys, HUNGARY Dr. A.K. Sundaram, Physical Research Lab, INDIA Dr. S.K. Trehan, Panjab University. INDIA Dr. Indra, Monan Lal Des, Ganaras HInd InIv, INDIA Or. L.K. Chavds, Sauth Gujarat UnIv, INDIA Dr. R.K. ChhajlanI. Var Ruchl Mara, INDIA B. Buti, Physical Research Lob, INDIA Dr. Phllilip Rosenau, Is roel Inst Tech, ISRAEL Prof. 5. Cupermon, Tel Aviv University, ISRAEL Prat. G. Rostagn i, Univ DI Padova, 1, LY Lidrarian, Int'l Ctr Theo Phys, ITALy Miss Ctella De Polo, as SOC EURATOA-CNEN, ITALY Bidlioteca, deI CNR ELRATOM, ITALY Dr. H. Yameto, Toshlba Res \& Dev, Japan Prot. M. Toshikana, JMERI, Tokai Ros Est, JAPAN Praf. T. Uchldo, Unlvers Ity of Tokyo, JAPAN Research Info Center, Nagoya Un Ivers Ity, JAPAN Prof. Kuojl Nishlkewa, Unlv of H] roshlmo, JaPAN SIgeru Mori, HAERI, JAPAN

LIBrory, Kyoto Unlvers Ity. JAPAN

Prof. Iehlro Kavakami, NInon UnIv, JAPAN

Prot. Sotoshl ltoh, Kyustiv Unluersity, JAPAN Teen into Division, Kores Atomlc Energy, KOREA Dr. R. Englend, Civdad Universitar la, MExico Blbliotheek, Fom-Inst Voor Plasma, NETHERLANDS Prof. 8.5. LIIVy, Unlvorsity of Walkato, NEW ZEALAND
Dr. Suresh C. Sharma, UnIr of Calobar, NIEERIA Prot. J.A.C. Cobrel, Inst Superlor Toeh, PORTUGA' Or. Octavian Patrus, ALI CUZA UniversIty, ROMANIA Dr. R. Jones, Nat'I Univ SI ngapore, SINGAPORE Prot. M.A. Hellberg, University of Natal, SO AFRICA Dr. Johen do Vllllers, Atomic Energy Bd, SO AFRICA Or. J,A, Toglo, JEN, SPAIN Prot. Man. Wi lhe Imson, Cralmars Un I Tech, SWEDEN Dr. Lennor Stentlo, Unlversity of MAEA, SWEDEN LIbrary. Royal Inst Tech, SWEDEN Dr. Erik T. Kerison, Uppsala UnIversitet, SWEDEN Contre de Recherchesen, Ecole Polytech Fed, 5wI TRERLAND Dr. W.L. Wolsa Nat'l Bur Stand, USA Dr. W.M. Stecey, Georg Ins T Tech, USA Dr. S.T. Wu, Unlv Alabemo, USA Mr. Norman L. Oleson, Univ 5 Florida, LSA Dr. Benjarin Mo, lawa State Univ, USA Magne Kristionsan, Texas Toch Univ, USA Dr. Roymond Askew, Auburn Univ, USA Dr. V.T. Tolok, Khorkov Phys Toch Ins, LSSR Dr. D.D. Ryutov, SIberlon Acod SCI, USSR Dr. M.S. Rablnovich, Lobedev Physlcel Inst, LSSR Dr. G.A. Ellseov, Kurchotov Institute, USSR Dr. V.A. Glukhlkh, Inst Electrothysicol, USSR Prot. T.J. Boyd, Univ College $N$ wales, WALES Or. K. Schindler. Ruhr Unlversitat, W. ERMANY Nucleor Res Estob, Julieh ltd, W. GERMANY Librarion, Maxplonck Institut, W. EePMany Dr. H.J. Kaeppler, University Stuttaart, W. GERMANY Blallothek, inst Plasmatorschung, W. GERMANY 